\title{
Lymphoma of pulmonary mucosa-associated lymphoid tissue: CT scan findings and pathological correlations
}

\author{
M. Wislez ${ }^{*, \$}$, J. Cadranel*\$,, M. Antoine ${ }^{\#, \$}$, B. Milleron*\$, M. Bazot ${ }^{+}$, C. Mayaud*\$, M-F. Carette ${ }^{+}$
}

Lymphoma of pulmonary mucosa-associated lymphoid tissue: CT scan findings and pathological correlations. M. Wislez, J. Cadranel, M. Antoine, B. Milleron, M. Bazot, C. Mayaud, M-F. Carette. C ERS Journals Ltd 1999.

ABSTRACT: The aim of this study was to describe the lesions of pulmonary mucosaassociated lymphoid tissue (MALT) lymphoma observed by means of computed tomography (CT) and to determine the value of CT in the management of this disease.

Sixty six CT scans were performed in 13 consecutive cases of histologically proven pulmonary MALT lymphoma at the time of diagnosis $(n=13)$ or periodically $(n=53)$. They were reviewed separately with chest radiographs by consensus between two observers. Pulmonary abnormalities were described and compared to histopathological findings on surgical specimens from seven patients.

At the time of diagnosis, elementary lesions observed by means of CT consisted of nodular areas of attenuation (12 of 13), linear areas of attenuation (eight of 13) and consolidations (six of 13). All these lesions were centred on airways that appeared dilated in seven cases and were more often bilateral and multiple on CT than on the chest radiographs. CT abnormalities correlated with gross pathological appearance and were related to a lymphomatous infiltration with a peribronchovascular distribution. Pathological examination also confirmed the presence of dilated airways within lymphomatous lesions and showed that the bronchial wall was respected. During follow-up, in patients on chemotherapy, response, relapse or progression were easily identified by means of plain radiography.

In the initial evaluation, computed tomography contributed to the choice of therapeutic strategy, avoiding unnecessary surgical resection in one-third of patients. By contrast, it is unclear whether computed tomography is useful for post-treatment follow-up of mucosa-associated lymphoid tissue.

Eur Respir J 1999; 14: 423-429.
*Services de Pneumologie et de Réanimation Respiratoire, ${ }^{+}$de Radiologie et $\mathrm{d}^{\prime}$ Anatomie-Pathologique, ${ }^{\text {S Laboratoire de }}$ Biologie Cellulaire et d'Immunopathologie Pulmonaire UPRES EA1531, Hôpital Tenon, Faculté Saint-Antoine, Université Paris VI, Paris, France.

Correspondence: J. Cadranel

Hôpital Tenon

4 rue de la Chine

75020 Paris

France

Fax: 33156016968

Keywords: Airway dilation

lung computed tomography scan mucosa-associated lymphoid tissue primary pulmonary lymphoma

Received: November 101998 Accepted after revision April 121999
Mucosa-associated lymphoid tissue (MALT) is usually absent from the normal human lung. However, it can be acquired during bronchial inflammatory processes and diseases involving chronic B cell dysfunction such as Sjögren's syndrome and rheumatoid arthritis $[1,2]$. Acquired MALT tissue can take the form of a benign lymphoid disorder (follicular bronchiolitis and lymphoid interstitial pneumonia), or a MALT lymphoma.

MALT lymphoma of the lung is rare, accounting for $<1 \%$ of all lymphomas [3]. It was long referred to as "pseudolymphoma". The advent of immunophenotyping and gene rearrangement analysis identified it as extranodal low-grade B cell primary pulmonary lymphoma (PPL), which is thought to originate from bronchial MALT [1, 3-5]. Such lymphomas are indolent in approximately half of the patients in whom the disease is discovered incidentally by means of radiography [6]. The diagnosis is usually made at a late stage, generally necessitating open lung biopsy [6]. Only symptomatic or extensive disease qualifies for treatment. Surgery is deemed feasible for single lesions or limited pulmonary involvement (single lobe) in patients with normal pulmonary function test results. In other settings, single-agent or low-dose combination chemotherapy is used palliatively [6].
The radiological abnormalities observed in low-grade PPL have been described in detail elsewhere [3, 6-13]. However, their precise characteristics and respective frequencies are difficult to determine from the literature, as medical imaging techniques and patient characteristics differ considerably from one series to another. Reports of pulmonary computed tomography (CT) findings are limited to a few isolated cases and a single large series, but detailed findings and the impact of CT on the management of pulmonary MALT lymphoma were not given [6, 14-18]. In order to fill these gaps, this study was conducted to: 1) determine pulmonary $\mathrm{CT}$ abnormalities at the time of diagnosis; 2) monitor changes during long-term follow-up; and 3) compare CT findings with histopathological findings obtained by means of open lung biopsy in 13 consecutive cases of histologically proven pulmonary MALT lymphoma.

\section{Patients and methods}

This study included all consecutive patients who had MALT lymphoma of the lung diagnosed between January 1989 and June 1997 in the chest department of our 
institution. The inclusion criterion was histopathologically proven MALT lymphoma of the lung without extrapulmonary node involvement. MALT lymphoma was defined [2] by the presence, on histopathological sections, of 1) low-grade B cell proliferation consisting of small centrocyte-like cells, even if few blast cells were visible, 2) associated with lymphoid follicles with germinal centres within the proliferation; and 3) lymphoepithelial lesions. Extrapulmonary lymphoma and chronic lymphocytic leukaemia were ruled out using a standardized diagnostic procedure including normal physical examination, complete blood cell count, chest radiography, abdominal ultrasound or CT, and bone marrow biopsy.

\section{Patients}

MALT lymphoma was diagnosed during the study period in 13 patients whose clinical features are listed in table 1. All the patients were seronegative for human immunodeficiency viruses. None were immunocompromised, but two had Sjögren's syndrome and one had disseminated acute lupus erythematosus. Two had had pulmonary tuberculosis.

The diagnosis of MALT lymphoma was based on open lung $(n=7)$ or transbronchial biopsy specimens $(n=5)$ in 12 patients in whom fibreoptic bronchoscopy results were normal. In one patient who had a tumour mass in the right lobar superior bronchus on fibreoptic bronchoscopy (case 11), the diagnosis was based on bronchial biopsies. As MALT lymphoma may involve several mucosal sites simultaneously, the usual MALT sites (salivary, lacrimal and thyroid glands and stomach) were routinely examined; gastric involvement was found in four patients and salivary gland involvement in one (table 1).

Three patients underwent surgical resection. Ten patients received chemotherapy, consisting of chlorambucil alone or a combination of cyclophosphamide, vindesine and prednisone. The median duration of follow-up was 40 months (9-102 months). The response to treatment was classified as complete response (CR), partial response (PR), progression or relapse, and was compared with the results of physical examination, the complete blood cell count, chest radiography and pulmonary $\mathrm{CT}$. The first assessment was made 3 months after surgery or the beginning of chemotherapy. The interval before subsequent assessments depended on the response ( $1 \mathrm{yr}$ for CR, 6 months for PR, and 3 months for relapse or progression). The three patients who underwent surgical resection are still in CR. During follow-up (table 1), three relapses occurred in two patients (all in PR), but transformation from low-grade to high-grade lymphoma never occurred.

\section{Computed tomography procedure}

Sixty-six CT scans were performed, at the time of diagnosis $(n=13)$ or periodically to assess the response to treatment $(\mathrm{n}=53)$, using either a Philips TX Tomoscan $(n=27)$ or a Philips SR Tomoscan $(n=39)$ (Philips Medical Systems, Best, the Netherlands). All the patients underwent conventional CT scans. Thin-section CT (1-mm or 2-mm sections, $10 \mathrm{~mm}$ apart) was used to identify groundglass attenuation and micronodule location. Scanning covered the apex of the lung to the costophrenic angles. The scanning times were $4 \mathrm{~s}$ and $1 \mathrm{~s}$ with the Philips TX and Philips SR devices, respectively. The matrix size was $512 \times 512$ pixels. All scans were obtained during suspended respiration at end-inspiratory volume. Patients were scanned in the supine position with their arms up. Intravenous contrast medium was used in 60 examinations. All images were displayed in a parenchymal window with a width of 1,600 $\mathrm{HU}$ and a level of $-600 \mathrm{HU}$, and in a mediastinal window with a width of $400 \mathrm{HU}$ and a level of 20 HU. Mediastinal images were immediately reconstructed using a standard algorithm, and parenchymal images were reconstructed retrospectively using a highspatial-frequency algorithm.

\section{Study design}

All chest radiograms and CT scans were obtained simultaneously and interpreted separately and independently by consensus between two observers (M. Wislez and M-F. Carette). Pulmonary abnormalities were described at the time of diagnosis on the basis of their number, extent and distribution, and were re-examined after treatment.

Table 1. - Clinical characteristics, treatment and follow-up of patients

\begin{tabular}{|c|c|c|c|c|c|c|c|}
\hline $\begin{array}{l}\text { Patient } \\
\text { No. }\end{array}$ & $\begin{array}{l}\text { Age } \\
\text { yrs }\end{array}$ & Sex & $\begin{array}{l}\text { Pre-existing } \\
\text { disease }\end{array}$ & Symptoms & $\begin{array}{l}\text { Mucosal } \\
\text { sites }\end{array}$ & Treatment & $\begin{array}{l}\text { Follow-up } \\
\text { months (response) }\end{array}$ \\
\hline 1 & 46 & M & None & None & None & chem & 102 (CR) \\
\hline 2 & 71 & M & Sjogrën's & WL, dysp & None & chem & 35 (Prog) \\
\hline 3 & 60 & $\mathrm{M}$ & None & None & None & chem & $78(\mathrm{PR})$ \\
\hline 4 & 62 & M & Prior PTB & None & Stomach & chem & 72 (PR) \\
\hline 5 & 74 & $\mathrm{~F}$ & $\mathrm{CHF}, \mathrm{GU}$ & WL, DC & Stomach & chem & 66 (CR) \\
\hline 6 & 65 & $\mathrm{M}$ & Sjogrën's & WL, DC & None & Surgery & $56(\mathrm{CR})$ \\
\hline 7 & 70 & $\mathrm{~F}$ & None & $\mathrm{WL}, \mathrm{DC}, \mathrm{Fv}_{\mathrm{V}}$ & Stomach & chem & 47 (CR) \\
\hline 8 & 77 & $\mathrm{~F}$ & Prior PTB & WL, Fv & None & Surgery & 40 (CR) \\
\hline 9 & 59 & $\mathrm{M}$ & None & $\mathrm{DC}$ & None & Surgery & $26(\mathrm{CR})$ \\
\hline 10 & 67 & $\mathrm{~F}$ & Asthma, lupus & None & None & chem & 18 (PR) \\
\hline 11 & 74 & M & None & $\mathrm{DC}$ & None & chem & 14 (CR) \\
\hline 12 & 39 & $\mathrm{~F}$ & None & WL, dysp, Fv & Stomach & chem & 13 (PR) \\
\hline 13 & 69 & $\mathrm{~F}$ & GU & None & Salivary gland & chem & 9 (PR) \\
\hline
\end{tabular}

M: male; F: female; Sjögren's: Sjögren's syndrome; PTB: pulmonary tuberculosis; CHF: congestive heart failure; GU: gastric ulcer; lupus: acute lupus erythematosus; WL: weight loss; dysp: dyspnoea; DC: dry cough; Fv: fever; chem: chemotherapy; CR: complete response; PR: partial response; Prog: progression (patient died). 
Table 2. - Chest radiography and computed tomography (CT) analysis at the time of diagnosis

\begin{tabular}{|c|c|c|}
\hline \multirow[b]{2}{*}{ Abnormalities } & \multicolumn{2}{|c|}{ Findings } \\
\hline & Radiographic $\mathrm{n}$ & CT $\mathrm{n}$ \\
\hline Bilateral/unilateral & $6 / 7$ & $9 / 4$ \\
\hline Multiple/single & $8 / 5$ & $10 / 3$ \\
\hline Masses & 5 & 5 \\
\hline Nodules & 2 & $7 *$ \\
\hline Micronodules & 3 & $8^{*}$ \\
\hline Ground-grass opacities & 0 & $5 *$ \\
\hline Consolidations & 6 & 6 \\
\hline Septal lines & 1 & 3 \\
\hline $\begin{array}{l}\text { Peribronchovascular interstitial } \\
\text { thickenings }\end{array}$ & 0 & $6^{*}$ \\
\hline Airways within the lesions & 5 & $13^{*}$ \\
\hline
\end{tabular}

${ }^{+}$: number of patients. ${ }^{*}: \mathrm{p}<0.05$ versus radiographic findings.

The following criteria were used to describe CT findings. Nodular areas of attenuation included micronodules ( $<7 \mathrm{~mm}$ in diameter), nodules $(>7$ and $<30 \mathrm{~mm}$ in diameter) and masses ( $>30 \mathrm{~mm}$ in diameter). Linear areas of attenuation included septal lines and peribronchovascular interstitial thickening. Consolidation was defined as an area of attenuation that was neither nodular nor linear, and which obscured the underlying vessels. Ground-glass opacity (GGO) was defined as a hazy increase in attenuation that did not obscure normal lung markings. A lesion was considered peripheral if located within 1-2 cm of any visceral pleural surface. Particular emphasis was placed on the detection of areas of low attenuation within all these lesions. Mediastinal and hilar lymphadenopathies and pleuropericardial abnormalities were also sought.

CT abnormalities were compared to histopathological findings on surgical specimens from seven patients (two lobectomy, one bilobectomy, four open lung biopsy). Each corresponding pathological lesion was analysed and its relationship to the anatomical structures was determined. Statistical comparisons were made using the Chi-squared test.

\section{Results}

\section{Pulmonary imaging features at diagnosis}

The results of chest radiography and CT $(n=13)$ are given in table 2 . Abnormalities were more often bilateral

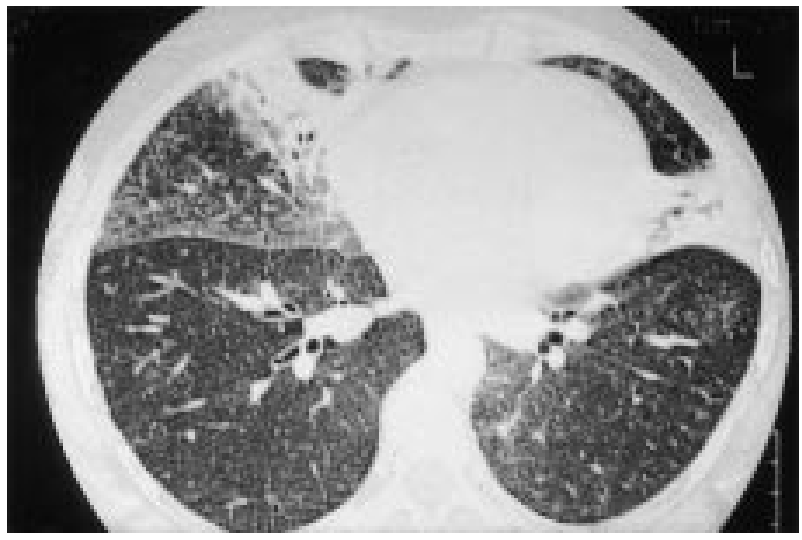

Fig. 1. - Axial computed tomography with 1-mm collimation (case 12) showed consolidations in the right middle lobe and left upper lobe, within which airways appeared dilated. Ground-glass opacity (GGO) and septal lines circumscribe the consolidation. Micronodules show a perilymphatic distribution. Notably, GGO and micronodules were also present in the left lower lobe.

and multiple on CT than on the chest radiographs, but the difference was not statistically significant (nine and 10, respectively, versus six and eight). However, CT facilitated the analysis of the number of small lesions (nodules, micronodules) and the morphology of primary lesions (GGO, peribronchovascular interstitial thickenings, airways within lesions) significantly better than chest radiography (table 2). CT also showed a centimetric $(\geq 1 \mathrm{~cm}$ in size) hilar lymph node in two cases. Atelectasis and pleural effusion were not seen on the chest radiographs or CT scans.

Primary lesions observed by means of CT consisted of linear areas of attenuation, nodular areas of attenuation and consolidations (table 3). No topographic predominance was observed: eight right upper lobe, nine right middle lobe, eight right lower lobe, eight left upper lobe, and eight left lower lobe.

Consolidations (fig. 1) were observed in six patients. Opacities were bilateral and peripheral in five cases. Areas of low attenuation were present in all the consolidations and were presumed to represent air bronchograms. The air bronchograms seemed to be dilated in three cases. No mucus- or fluid-filled dilated bronchi or CT-angiogram signs were seen. Nodular areas of attenuation (fig. 2) were observed in 12 patients. These findings were classified as

Table 3. - Pulmonary computed tomography analysis at the time of diagnosis

\begin{tabular}{|c|c|c|c|c|c|c|c|c|c|c|c|c|c|}
\hline & \multicolumn{13}{|c|}{ Patient No. } \\
\hline & 1 & 2 & 3 & 4 & 5 & 6 & 7 & 8 & 9 & 10 & 11 & 12 & 13 \\
\hline Consolidation* & - & $6(\mathrm{ab})$ & - & - & $3(\mathrm{ab} / \mathrm{aB})$ & - & $1(\mathrm{a} / \mathrm{b})$ & $3(\mathrm{ab} / \mathrm{aB})$ & - & - & - & $7(\mathrm{ab} / \mathrm{aB})$ & $1(\mathrm{ab})$ \\
\hline \multicolumn{14}{|c|}{ Nodular area of attenuation } \\
\hline masses* & $2(2 b / 2 B)$ & - & $2(2 b / 1 B)$ & $2(2 \mathrm{~b} / 2 \mathrm{~B})$ & - & - & - & - & $1(1 \mathrm{~b} / 1 \mathrm{~B})$ & - & $1(1 b)$ & - & - \\
\hline nodules* & - & $1(1 b)$ & $1(1 b)$ & $3(3 b)$ & $2(1 b)$ & - & $4(0 \mathrm{~b})$ & - & - & $7(1 b)$ & - & - & $4(2 b)$ \\
\hline micronodules & + & + & - & - & + & - & - & + & - & + & + & + & + \\
\hline \multicolumn{14}{|l|}{ Ground-grass } \\
\hline opacities & - & - & - & + & + & - & - & - & + & + & - & + & - \\
\hline Linear area of & & & & & & & & & & & & & \\
\hline attenuation & + & - & + & + & + & + & - & - & - & + & - & + & + \\
\hline
\end{tabular}

*: number of lesions. The number of lesions within which airways could be seen is indicated as air bronchogram (ab) for consolidations or as bronchocentric lesions (b) for nodules or masses. Airway dilation is specified by B or aB. The margins of the lesions were analysed for the presence of micronodules or ground-glass opacity. +: present; -: absent. 

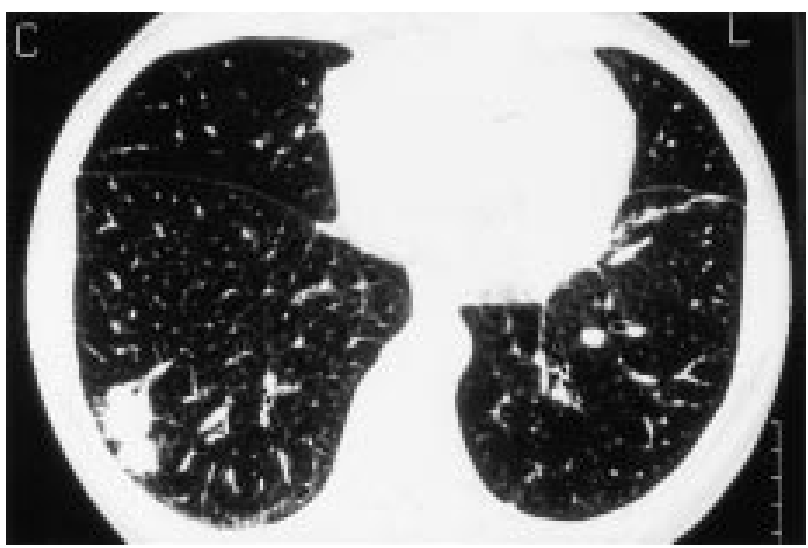

Fig. 2. - Axial computed tomography with 1-mm collimation (case 10) showed two peripheral nodules in the right lower lobe. A small bronchus could be seen at the edge of the largest of the nodules. Peribronchovascular interstitial thickening, nodules and septal lines were present in the left lower lobe.

masses $(n=5)$, nodules $(n=7)$ or micronodules $(n=8)$. Masses were central, with a peribronchovascular distribution. Areas of low attenuation were seen within all of the masses and were presumed to represent airways. These airways seemed to be markedly dilated in all of the masses except one (case 11). The largest mass was $8 \mathrm{~cm}$ in diameter (case 9). Nodules were mostly peripheral and were also centred on airways. A mean of 2.3 (range 1-7) nodules and/or masses per patient were detected. On thin sections, micronodules and GGO surrounded areas of attenuation, with a lymphatic distribution (fig. 1). GGO appeared to result from the coalescence of these micronodules. Linear areas of attenuation were observed in eight patients. They consisted of peribronchovascular interstitial thickening $(n=6)$ and septal lines $(n=3)$.

\section{Pulmonary imaging features during follow-up (n=53)}

Follow-up of the three patients who underwent surgery showed no signs of relapse. Among the 10 patients on chemotherapy, one progressed and had a specific pattern of change, with centrifugal development of the initial bilateral consolidations (case 2). In the four patients in CR, the lesions disappeared, with complete normalization of airways. In the five patients in PR, the lesions shrank but the dilated bronchi and/or bronchioles located within the lesions did not always disappear (fig. 3). Three relapses occurred. The lesions had the same appearance as the primary lesions and were located at the initial site, except in one patient who developed a lesion in a new site. Results of analysis of the mediastinum remained normal. Two patients who initially had bronchiectasis outside the presumed lymphomatous lesions (cases 5 and 10) did not develop areas of attenuation around them. The bronchiectasis did not regress.

During this follow-up, there was no disagreement between chest radiography and $\mathrm{CT}$ in assessing response to treatment. Indeed, the results of the CT scan did not alter the assessment of the response to treatment classified by
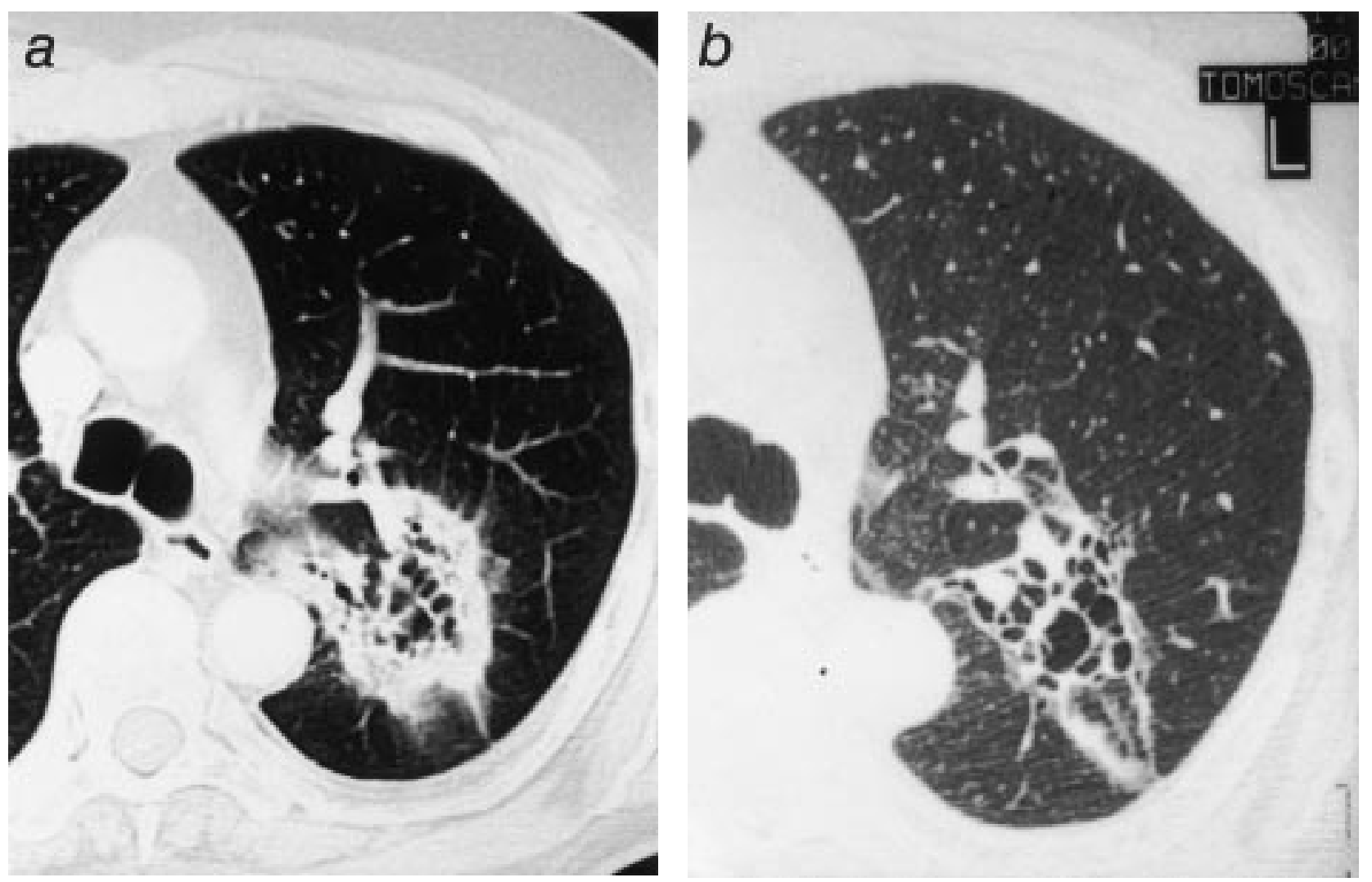

Fig. 3. - Axial computed tomography with 1-mm collimation (case 4) showed: a) a mass in the left upper lobe centred on markedly dilated bronchi at the time of diagnosis; and b) the same patient after $1 \mathrm{yr}$ of chemotherapy. The initial mass in the left upper lobe shrank but the cluster of dialted bronchi remained. 

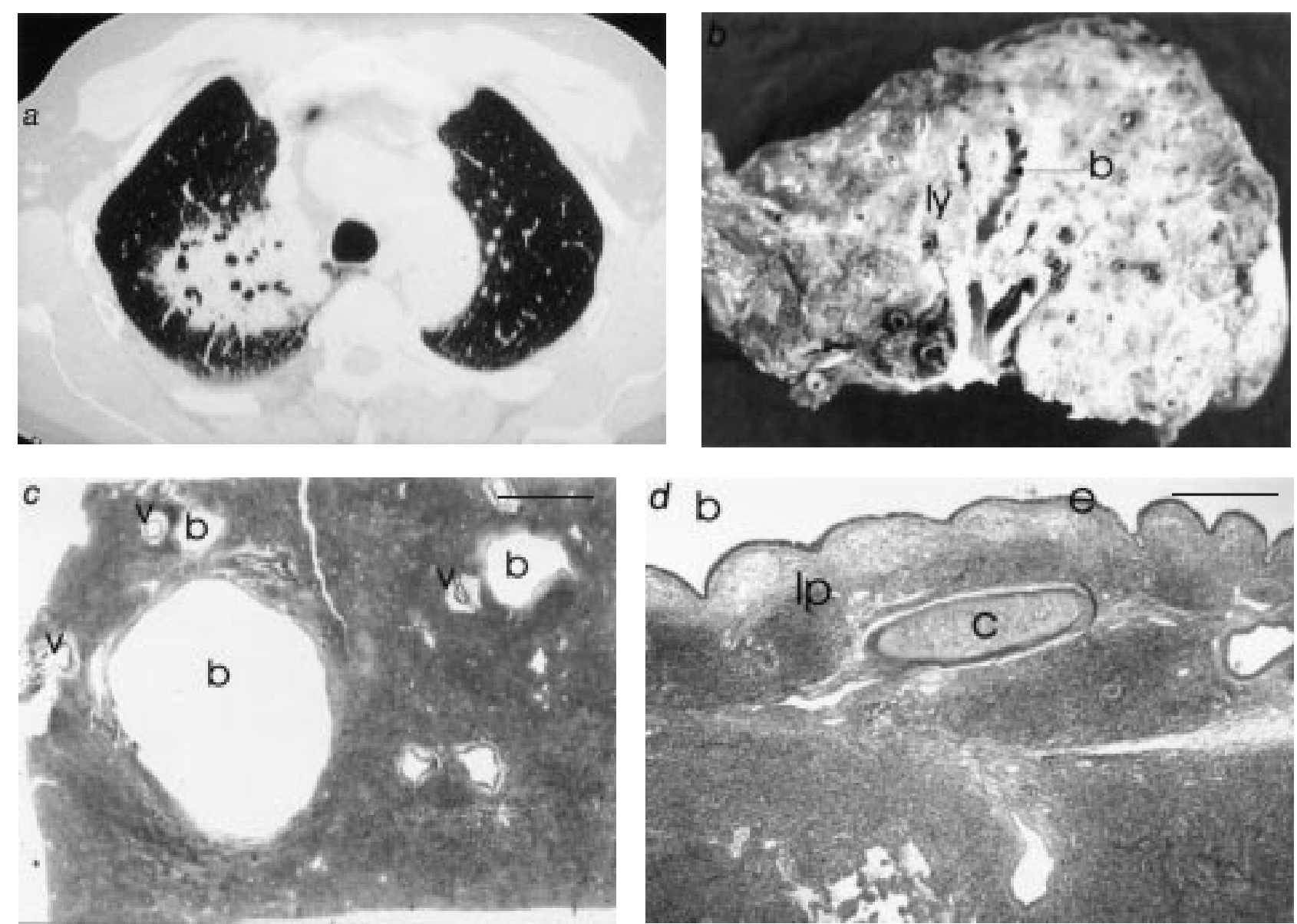

Fig. 4. - Histopathological correlation of areas of low attenuation, pressumed to represent dilated bronchi, within a mass in the right upper lobe (case 9): a) axial computed tomography of case 9 with $10-\mathrm{mm}$ collimation; b) longitudinal section of the mass showing enlarged and irregular bronchi within a pale grey area of dense lymphomatous infiltration; c) histopathological findings on a transverse section in which the bronchiolar lumen appears ectatic in relation to adjacent arteriole lumina (Haematoxylin/eosin/safranin staining, internal scale bar $=2 \mathrm{~mm}$ ) and d) histopathological findings on a longitudinal section at higher magnification. The bronchial wall is intact, and the integrity of the bronchial epithelium, lamina propria and cartilaginous tissue is mainatained. (Haematoxylin/eosin/safranin in staining, internal scale bar=2 mm.) b: bronchial lumina; ly: lymphoma; v: vessel lumen; e: epithelioma; lp: lamina propria; c: cartilage.

chest radiography in term of CR, PR, relapse or progression and did not result in a modification the treatment regimen. However, CT was more precise than chest radiography in describing morphological changes in lesions such as the airways dilatation.

\section{Correlations between pulmonary computed tomography and histopathological findings}

Histopathological specimens corresponding to CT regions of interest were available for examining consolidations $(n=3)$, linear areas of attenuation $(n=1)$ and nodular areas of attenuation $(n=4)$. CT abnormalities correlated with the gross pathological appearance (fig. 4a and b) but, whatever the CT abnormalities, the corresponding pathological sample had the same microscopic appearance, showing lymphomatous infiltration with a peribronchovascular distribution (fig. 5). However, differences in the extent and location of the lymphomatous infiltration accounted for the differences in the macroscopic features as depicted on CT. Indeed, lymphomatous infiltration caused smooth or nodular interstitial thickening, which showed up on CT as masses or peribronchovascular thickening in the central interstitium, and as septal lines, nodules or consolidations in the peripheral interstitium. Histological examination revealed that GGO and micronodules resulted from lymphomatous infiltration of the interlobular septa and interalveolar walls, forming the lymphangitic pattern located at the periphery of the tumour (case 10, fig. 5). In one case, the pathological sample corresponding to a consolidation also showed nonspecific lesions such as fibrosis, nonspecific alveolitis and/or organizing pneumonia associated with the lymphomatous proliferation (case 2).

The presence of dilated bronchi and/or bronchioles, initially suspected in three patients (cases 1, 8 and 9; fig. 4a and b), was clearly confirmed on histopathological sections. Bronchial and/or bronchiolar lumina became rounded and ectatic compared to adjacent vessel lumina (fig. $4 \mathrm{c}$ and d). There was no destruction of the bronchial wall or tumour necrosis. Histopathological analysis also demonstrated the presence of bronchial and/or bronchiolar dilatation in samples corresponding to a peripheral bronchocentric nodule (case 10) and to proximal peribronchovascular thickening (case 6). These dilated airways appeared to result from alveolar collapse or destruction of the peribronchial parenchyma due to lymphomatous infiltration. 


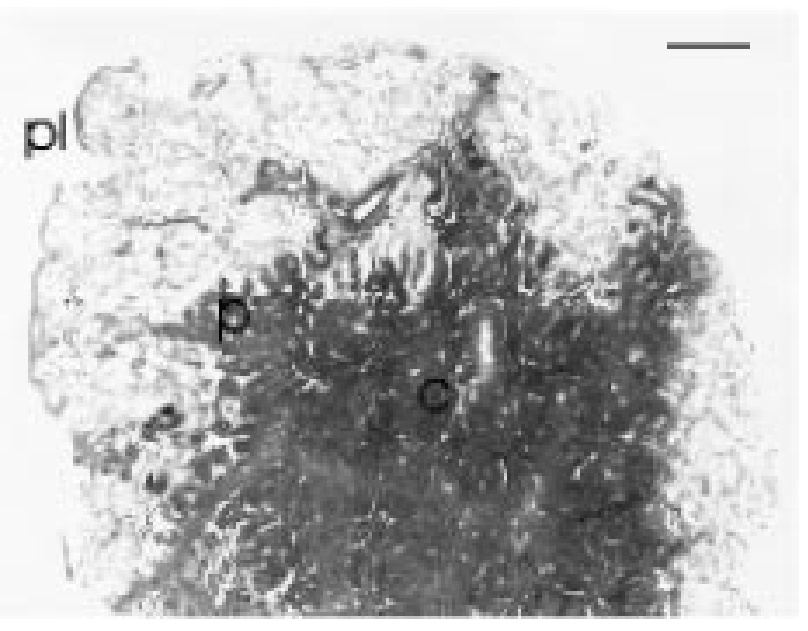

Fig. 5. - Hystopathological correlation of the ill-defined nodule in case 10 (fig. 1) showing the central and peripheral zone of the nodule, the latter corresponding to the lymphoma spreading within interlobular septa (Haematoxylin/eosin/safranin) pl: pleura; c: centre; p: periphery. (Internal scale bar $=500 \mu \mathrm{m}$.)

\section{Discussion}

PPL usually appears on chest radiographs and CT scans as one or more well-defined nodules or masses ranging 2$10 \mathrm{~cm}$ in diameter, often with an air bronchogram inside the pulmonary lesion [3, 6-18]. Pulmonary CT was more precise in this study as regards the morphology, extent and distribution of the primary lesions. MALT lymphoma of the lung appeared as nodular areas of attenuation $(92 \%$ of cases), linear areas of attenuation ( $61 \%$ of cases) and consolidations ( $46 \%$ of cases), with no marked tendency towards an apicobasal distribution (table 3). Unlike chest radiography, CT showed that all of these lesions were centred on air-filled airways and that most were surrounded by GGO and/or micronodules (table 3 ). Imaging findings corresponded to histological lymphomatous proliferation, which always had a peribronchovascular distribution. These findings are similar to those described in processes with lymphatic involvement, such as sarcoidosis, Kaposi's sarcoma, carcinomatosis lymphangitis and, especially, pulmonary dissemination of nodal lymphoma [19-23]. However, they also differed in several respects. CT analysis of these pulmonary MALT lymphomas did not show pleural effusion, tumour necrosis or atelectasis. Furthermore, hilar and mediastinal lymphadenopathy were rare at the time of diagnosis and remained centimetric even after lengthy follow-up (9-102 months) and during relapse. This was the case even in the patient who died as a result of disease progression.

CT is necessary to confirm the absence of mediastinal involvement, and could be helpful in assessing the extent of a suspected MALT lymphoma of the lung at the time of diagnosis. Previous studies based on chest radiography showed that pulmonary lesions were bilateral and multiple in $9-40 \%$ and $12-53 \%$ of cases, respectively [3, 6-13]. In the present series, CT was more sensitive than chest radiography, showing the presence of GGO, micronodules and peribronchovascular thickening $(\mathrm{p}<0.05)$. In addition, lesions were more often bilateral and multiple on CT than on chest radiography (table 2). Although CT was not significantly superior in detecting bilateral extension in this series, it nonetheless avoided surgical resection in three of the seven patients in whom chest radiography showed unilateral involvement. By contrast, it is unclear whether CT is useful for post-treatment follow-up of MALT lymphoma of the lung. First, no pulmonary recurrence was observed in patients treated using surgery. Secondly, the results of the pulmonary and mediastinal evaluation did not differ between $\mathrm{CT}$ and plain radiography during follow-up of patients treated with chemotherapy. Finally, almost all of the relapses occurred at the initial site, and had the same appearance as the original lesions.

MALT lymphoma of the lung should be considered as a possible diagnosis when CT shows areas of low attenuation within lesions, regardless of their pattern. MALT lymphoma, as well as bronchioloalveolar carcinoma and organizing pneumonia, is usually listed among the differential diagnoses of chronic consolidations containing an air bronchogram [6]. MALT lymphoma should also be included in the differential diagnosis of a nodule or mass containing an area of low attenuation, together with Wegener's disease, rheumatoid nodules, cancer and abscesses [24, 25]. However, true cavitation is generally observed in histological studies of these latter conditions, whereas the areas of low attenuation observed in MALT lymphoma always corresponded to normal or dilated airways on pathological sections and never to necrosls.

The present results suggest that the bronchial dilation observed in MALT lymphoma differs strongly from bronhiectasis in that: 1) the patients did not produce sputum (table 1);2) bronchial dilatation was always surrounded by a mass or consolidation (findings generally absent on CT scans of bronchiectasis [26]); 3) the bronchial dilation sometimes disappeared during treatment, while bronchiectasis is usually irreversible [26]; and 4) pathological studies showed no destruction of the bronchial wall, in contrast to the permanent bronchial wall alterations observed in bronchiectasis, suggesting that bronchial or bronchiolar dilation resulted from the collapse and destruction of the peribronchial parenchyma secondary to lymphomatous proliferation [27]. Finally, bronchial disorders observed in diseases with $\mathrm{B}$ cell alterations probably result either from local immune deficiency followed by bronchial suppuration and the formation of bronchiectasis such as in hypogammaglobulinaemia [28] or rheumatoid arthritis [29], or from local B cell activation/proliferation processes such as in Sjögren's syndrome [30], lymphoid interstitial pneumonia, [31, 32] or MALT lymphoma.

This study clearly demonstrates that computed tomography has a pivotal role in the initial evaluation of patients with mucosa-associated lymphoid tissue lymphoma of the lung in ruling out hilar or mediastinal adenopathy, showing characteristic lesions (i.e. airways within areas of attenuation, regardless of their pattern) and contributing to the choice of therapeutic strategy. By contrast, computed tomography appears to be far less useful during posttreatment follow-up.

Acknowledgements. The authors thank C. Bouleuc, J-P. L'huillier and M. Prosper for their clinical contribution and C. Bonnement, V. Chassagne and $\mathrm{H}$. Dubesset for their technical assistance.

\section{References}

1. Addis BJ, Hyjek E, Isaacson PG. Primary pulmonary lymphoma: a re-appraisal of its histogenesis and its 
relationship to pseudolymphoma and lymphoid interstitial pneumonia. Histopathology 1988; 13: 1-17.

2. Isaacson PG, Norten AJ. Malignant lymphoma of the lung. In: Livingstone C, ed. Extranodallymphoma. New York, 1994: 85-102.

3. L'Hoste RJ, Filippa DA, Lieberman PH, Bretsky S. Primary pulmonary lymphomas. A clinicopathologic analysis of 36 cases. Cancer 1984; 54: 1397-1406.

4. Li G, Hansmann ML, Zwingers T, Lennert K. Primary lymphomas of the lung: morphological, immunohistochemical and clinical features. Histopathology 1990; 16: 519-531.

5. Fiche M, Capron F, Berger F, Galateau F, Cordier JF, Loire R, Diebold J. Primary pulmonary non-Hodgkin's lymphomas. Histopathology 1995; 26: 529-537.

6. Cordier JF, Chailleux E, Lauque D, et al. Primary pulmonary lymphomas. A clinical study of 70 cases in nonimmunocompromised patients. Chest 1993; 103: 201-208.

7. Le Tourneau A, Audouin J, Garbe L, et al. Primary pulmonary malignant lymphoma, clinical and pathological findings, immunocytochemical and ultrastructural studies in 15 cases. Haematol Oncol 1983; 1: 49-60.

8. Kennedy JL, Nathwani BN, Burke JS, Hill LR, Rappaport H. Pulmonary lymphomas and other pulmonary lymphoid lesions. A clinicopathologic and immunologic study of 64 patients. Cancer 1985; 56: 539-552.

9. Julsrud PR, Brown LR, Li CY, Rosenow EC, Rosenow D, Crowe JK. Pulmonary processes of mature-appearing lymphocytes: pseudolymphoma, well-differentiated lymphocytic lymphoma, and lymphocytic interstitial pneumonitis. Radiology 1978; 127: 289-296.

10. Marchevsky A, Padilla M, Kaneko M, Kleinerman J. Localized lymphoid nodules of lung. A reappraisal of the lymphoma versus pseudolymphoma dilemma. Cancer 1983; 51: 2070-2077.

11. Turner RR, Colby TV, Doggett RS. Well-differentiated lymphocytic lymphoma. A study of 47 patients with primary manifestation in the lung. Cancer 1984; 54: 20882096.

12. Peterson H, Snider HL, Yam LT, Bowlds CF, Arnn EH, Li CY. Primary pulmonary lymphoma. A clinical and immunohistochemical study of six cases. Cancer 1985; 56: 805-813.

13. Koss MN, Hochholzer L, Nichols PW, Wehunt WD, Lazarus AA. Primary non-Hodgkin's lymphoma and pseudolymphoma of lung: a study of 161 patients. Hum Pathol 1983; 14: 1024-1038.

14. Bolton-Maggs PH, Colman A, Dixon GR, Myskow MW, Williams JG, Donnelly RJ, Hind CR. Mucosa associated lymphoma of the lung. Thorax 1993; 48: 670-672.

15. Bosanko CM, Korobkin M, Fantone JC, Rubin SB, Lynch JP. Lobar primary pulmonary lymphoma: CT findings. $J$ Comput Assist Tomogr 1991; 15: 679-682.
16. Lazar EB, Whitman GJ, Chew FS. Lymphoma of bronchus-associated lymphoid tissue. Am J Roentgenol 1996; 167: 116.

17. Vincent JM, Ng YY, Norton AJ, Armstrong P. CT "angiogram sign" in primary pulmonary lymphoma. $J$ Comput Assist Tomogr 1992; 16: 829-831.

18. Canver CC. Primary B-cell malignant lymphoma of the lung. Ann Thorac Surg 1993; 56: 964-966.

19. Lewis ER, Caskey CI, Fishman EK. Lymphoma of the lung: CT findings in 31 patients. Am J Roentgenol 1991; 156: 711-714.

20. Fishman EK, Kuhlman JE, Jones RJ. CT of lymphoma: spectrum of disease. Radiographics 1991; 11: 647-669.

21. North LB, Libshitz HI, Lorigan JG. Thoracic lymphoma. Radiol Clin North Am 1990; 28: 745-762.

22. Brauner MW, Grenier P, Mompoint D, Lenoir S, de Cremoux H. Pulmonary sarcoidosis: evaluation with highresolution CT. Radiology 1989; 172: 467-471.

23. Traill ZC, Miller RF, Shaw PJ. CT appearances of intrathoracic Kaposi's sarcoma in patients with AIDS. $\mathrm{Br}$ J Radiol 1996; 69: 1104-1107.

24. Trigaux JP, Gevenois PA, Goncette L, Gouat F, Schumaker A, Weynants P. Bronchioloalveolar carcinoma: computed tomography findings. Eur Respir J 1996; 9: 9-11.

25. Zwirewich CV, Vedal S, Miller RR, Muller NL. Solitary pulmonary nodule: highresolution CT and radiologicpathologic correlation. Radiology 1991; 179: 469-476.

26. McGuiness G, Naidich DP, Leitman BS, DI M. Bronchiectasis: CT evaluation. Am J Roentgenol 1993; 160: 253-259.

27. Corrin B. The lungs, 2nd ed. Churchill Livingstone, New York, 1990; 169-171.

28. Hermaszewski RA, Webster ADB. Primary hypogammaglobulinemia: a survey of clinical manifestations and complications. QJM 1993; 86: 31-42.

29. Anaya JM, Diethelm L, Ortz LA, Gutierrez M, Citera G, Welsh RA, Espinoza LR. Pulmonary involvement in rheumatoid arthritis. Semin Arthritis Rheum 1995; 24: 242-254.

30. Franquet T, Gimenez A, Monill JM, Diaz C, Geli C. Primary Sjogren's syndrome and associated lung disease: CT findings in 50 patients. Am J Roentgenol 1997; 169: 655-658.

31. Amorosa JK, Miller RW, Laraya-Cuasay L, et al. Bronchiectasis in children with lymphocytic interstitial pneumonia and acquired immune deficiency syndrome. Plain film and CT observations. Pediatr Radiol 1992; 22: 603606.

32. Ichikawa Y, Kinoshita M, Koga T, Oizumi K, Fujimoto K, Hayabuchi N. Lung cyst formation in lymphocytic interstitial pneumonia: CT features. J Comput Assist Tomogr 1994; 18: 745-748. 